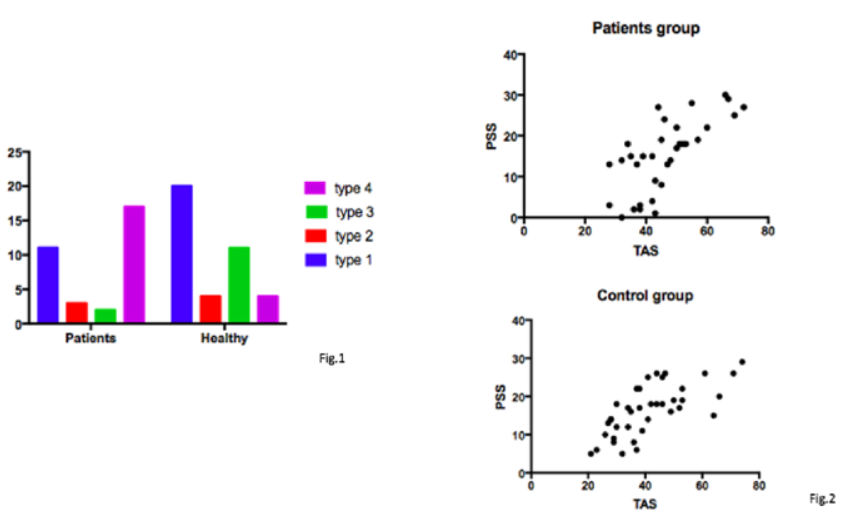

Disclosure of Interests: None declared

DOI: 10.1136/annrheumdis-2021-eular.1725

\section{AB0822 1 BREASTFEEDING AMONG WOMEN WITH RHEUMATIC DISEASES: ANALYSIS OF DATA FROM THE P-RHEUM. IT STUDY}

S. Panaro ${ }^{1}$, M. C. Gerardi ${ }^{1}$, M. Filippini ${ }^{1}$, F. Crisafulli ${ }^{1}$, M. Fredi ${ }^{1}$, R. Gorla ${ }^{1}$, M. G. Lazzaroni ${ }^{1}$, D. Lini' ${ }^{1}$, C. Nalli ${ }^{1}$, L. Moschetti ${ }^{1}$, F. Regola ${ }^{1}$, M. Taglietti ${ }^{1}$, A. Bortoluzzi ${ }^{2}$, A. Zanetti ${ }^{3}$, A. Lojacono ${ }^{4}$, S. Zatti ${ }^{4}$, C. A. Scirè ${ }^{2}$, G. Carrara ${ }^{3}$, F. Ramazzotto ${ }^{4}$, L. Andreoli ${ }^{1}$, F. Franceschini ${ }^{1}$, A. Tincani' ${ }^{1}$ on behalf of SIR. ${ }^{1}$ University of Brescia, Spedali Civili of Brescia, Rheumatology Unit, Brescia, Italy; ${ }^{2}$ Ulniversity of Ferrara, Rheumatology Unit, Ferrara, Italy; ${ }^{3}$ Italian Society for Rheumatology, Epidemiology Unit, MIlan, Italy; ${ }^{4}$ Spedali Civili of Brescia, Obsterics and Gynceology Unit, Brescia, Italy

Background: The World Health Organization recommends that infants should be exclusively breastfed until the age of 6 months. The aim of this study was to assess the ratio of breastfeeding patients with Rheumatic Diseases (RD) and to identify possible causes of its discontinuation.

Objectives: The aim of this study was to assess the ratio of breastfeeding patients with Rheumatic Diseases (RD) and to identify possible causes of its discontinuation.

Methods: This study was embedded in the P-RHEUM.it register, as a nationwide prospective cohort study collecting data of pregnancies in inflammatory RD. Pregnancies, enrolled until the 20th week of pregnancy, are followed from pregnancy until 6 months postpartum. At baseline, sociodemographic parameters, obstetric history, comorbidities are reported. During pregnancy, the course of maternal disease, development of foetus and complications are reported. After delivery, the pregnancy outcome, data on lactation and child development are collected.

Results: From May 2018 to May 2020 data of 349 patients were available. Data on lactation were available in 44 pregnancies. Two months after delivery 37 were continuing breastfeeding $(n=26)$ or mixed feeding $(n=11)$, while 7 were using formula feeding. Among patients using formula feeding 2 had a diagnosis of rheumatoid arthritis (RA), 1 of juvenile idiopathic arthritis, 1 of undifferentiated arthritis (UA), 1 of anti-phospholipid syndrome (APS), 1 of vasculitis and 1 of systemic lupus erythematosus. The reasons of formula feeding were the following: 2 for agalactia, 2 for personal preferences, 3 for drug-related concerns ( 1 for physician's decision in a patient with APS; 2 for maternal concerns about drugs in patients with RA and UA treated respectively with Adalimumab and Tocilizumab). At 6 months 30 continued breastfeeding $(n=23)$ or mixed feeding $(n=7)$ and 14 formula feeding. The reasons of formula feeding were available in 9 patients: 3 for agalactia, 2 for personal preferences, 2 for physician's decision in a patient with APS and in a patient positive for anti-phospholipid antibodies; 2 for maternal concerns about drugs. Conclusion: Preliminary data of this prospective study demonstrate a high percentage of breastfeeding/mixed feeding after delivery and after 6 months among women with RD. Drug related concerns are the main reason of discontinuation of breastfeeding, although medication results compatible with lactation. Using our results, strategies supporting patients with RD whishing to breastfeed may be developed.

\section{REFERENCES:}

[1] Carina Gotestam Sporken et al. The EULAR points to consider for use of antirheumatic drugs before pregnancy, and during pregnancy and lactation. Ann Rheum Dis 2016.

[2] Sammaritano et al. 2020 American College of Rheumatology Guideline for the management of reproductive health in rheumatic and muscoloskeletal diseases, Arthritis Rheumatol. 2020

Acknowledgements: Authors would like to thank SIR study center and all patients who accepted to partecipate to our study
Disclosure of Interests: None declared

DOI: 10.1136/annrheumdis-2021-eular.1814

\begin{tabular}{|l|l|}
\hline AB0823 & TREATMENT WITH ADALIMUMAB IN PATIENTS \\
WITH CHRONIC INFLAMMATORY RHEUMATIC \\
DISEASES: A STUDY OF TREATMENT \\
TRAJECTORIES ON A PATIENT LEVEL IN \\
CLINICAL PRACTICE
\end{tabular}

I. Redeker ${ }^{1}$, S. Moustakis ${ }^{2}$, S. Tsiami ${ }^{2}$, X. Baraliakos ${ }^{2}$, I. Andreica ${ }^{2}$, B. Buehring ${ }^{2}$, J. Braun ${ }^{2}$, U. Kiltz ${ }^{2}{ }^{1}$ Deutsches Rheuma-Forschungszentrum Berlin (DRFZ), Epidemiology, Berlin, Germany; ${ }^{2}$ Rheumazentrum Ruhrgebiet at Ruhr-University Bochum, Rheumatology, Herne, Germany

Background: There is evidence that drug retention rates to adalimumab (ADA) in patients (pts.) with chronic inflammatory rheumatic diseases (CIRD) are impaired by loss of efficacy and adverse events, and that about $50 \%$ of users had discontinued ADA within 5 years (1). With the introduction of ADA biosimilars in October 2018, non-medical switching from originator to ADA biosimilars is now increasingly part of daily practice in rheumatologic care.

Objectives: The aim was to study treatment trajectories over two years in pts. with CIRD receiving originator ADA.

Methods: Pts. with CIRD on originator ADA who switched to ADA biosimilar from October 2018 onwards were identified and followed until 2020. Disease activity (ASDAS), physical function (HAQ, BASFI), and changes in treatment were documented every 3 months. The four predefined treatment trajectories "continued ADA biosimilar therapy", "back-switch to originator ADA therapy", "switch to other biological (b) disease modifying anti-rheumatic drug (DMARD) therapy", and "stopped bDMARD therapy /death /drop out" were used to compare characteristics of pts. with different trajectories.

Results: A total of 111 CIRD pts. on treatment with originator ADA were switched to ADA biosimilar (Table 1). The majority of pts. 75 continued therapy with ADA biosimilar (Figure 1 next page) while 16\% switched back to originator ADA, $7 \%$ switched to a different bDMARD, and $9 \%$ either stopped treatment $(n=9)$ or died $(n=1)$. Pts. who continued ADA biosimilar were more frequently male, older or with a longer disease duration than those who switched therapy back to originator ADA and those who switched to a different bDMARD (Table 1). The previous duration on originator ADA treatment was increased in patients who continued ADA biosimilar compared to those who switched therapy back to originator ADA and those who switched to a different bDMARD. There was more functional impairment (HAQ, BASFI) and higher disease activity (ASDAS) in pts. who switched compared to those who continued ADA biosimilar therapy (Table 1). Treatment with csDMARDs and glucocorticoids was increased in pts. who continued ADA biosimilar therapy, while pts. who switched therapy had more previous bDMARD therapies (Table 1).

Table 1. Characteristics of patients at baseline for the entire group and stratified by treatment trajectory

\begin{tabular}{|c|c|c|c|c|c|}
\hline & \multirow[b]{2}{*}{$\begin{array}{c}\text { Total } \\
\text { group } \\
\mathrm{N}=111 \\
(100 \%)\end{array}$} & \multicolumn{4}{|c|}{ Treatment trajectory } \\
\hline & & $\begin{array}{c}\text { continued } \\
\text { ADA biosim- } \\
\text { ilar therapy } \\
\mathrm{N}=75(67.6 \%)\end{array}$ & $\begin{array}{c}\text { back-switch } \\
\text { to originator } \\
\text { ADA therapy } \\
\mathrm{N}=18 \\
(16.2 \%)\end{array}$ & $\begin{array}{l}\text { switch to } \\
\text { different } \\
\text { bDMARD } \\
\text { therapy } \\
\mathrm{N}=8(7.2 \%)\end{array}$ & $\begin{array}{c}\text { no } \\
\text { bDMARD } \\
\text { therapy / } \\
\text { death / } \\
\text { drop out } \\
\mathrm{N}=10(9.0 \%)\end{array}$ \\
\hline Age, y & $51.2(14.5)$ & $51.5(13.6)$ & $50.6(16.8)$ & 43.5 (9.5) & $56.4(19.0)$ \\
\hline Women, No. (\%) & $46(41.4)$ & $27(36.0)$ & $9(50.0)$ & $6(75.0)$ & $4(40.0)$ \\
\hline RA & $23(20.7)$ & $17(22.7)$ & $2(11.1)$ & $1(12.5)$ & $3(30.0)$ \\
\hline axSpA & 68 (61.3) & 47 (62.7) & $11(61.1)$ & $6(75.0)$ & $4(40.0)$ \\
\hline PsA & 15 (13.5) & $7(9.3)$ & $4(22.2)$ & $1(12.5)$ & $3(30.0)$ \\
\hline Other diagnoses & $5(4.5)$ & $4(5.3)$ & $1(5.6)$ & $0(0.0)$ & $0(0.0)$ \\
\hline $\begin{array}{l}\text { Disease duration, } \\
\text { median (IQR), y }\end{array}$ & $5.0(2.0-8.0)$ & $5.0(2.0-9.0)$ & $3.5(2.0-6.0)$ & $2.0(1.0-5.5)$ & $4.5(2.0-8.0)$ \\
\hline $\begin{array}{l}\text { Duration previous } \\
\text { originator ADA } \\
\text { therapy }\end{array}$ & $40.7(27.7)$ & $45.3(27.8)$ & $35.0(25.2)$ & $20.3(24.7)$ & $32.3(25.1)$ \\
\hline DAS28 & $3.0(1.0)$ & $2.9(1.0)$ & $3.4(1.0)$ & - & $3.3(1.2)$ \\
\hline $\begin{array}{l}\text { CRP, median (IQR), } \\
\text { mg/L }\end{array}$ & $0.2(0.1-0.3)$ & $0.1(0.1-0.2)$ & $0.2(0.0-0.5)$ & $0.2(0.2-1.3)$ & $0.3(0.2-0.4)$ \\
\hline HAQ score & $1.3(0.8)$ & $1.1(0.7)$ & $1.7(0.8)$ & - & $1.8(1.0)$ \\
\hline ASDAS & $2.2(1.1)$ & $2.0(1.0)$ & $3.0(1.2)$ & $2.7(0.9)$ & $2.3(0.2)$ \\
\hline BASFI & $3.5(2.6)$ & $3.0(2.5)$ & $5.4(2.4)$ & $3.4(1.6)$ & $5.4(1.6)$ \\
\hline
\end{tabular}

+values are given as mean (SD)

Conclusion: Two thirds of pts. who switched to ADA biosimilar remained on this therapy for 2 years. As many as $16 \%$ of pts. switched back to ADA originator. Whether or to what degree this was influenced by nocebo effects needs further 
study. The same is true for the effect of functional impairment - it would be interesting to know whether this was due to inflammation or structural damage. REFERENCES:

[1] Neovius M et al. Ann Rheum Dis 2015; 74:354-360

[2] The study was funded by Hexal Germany.

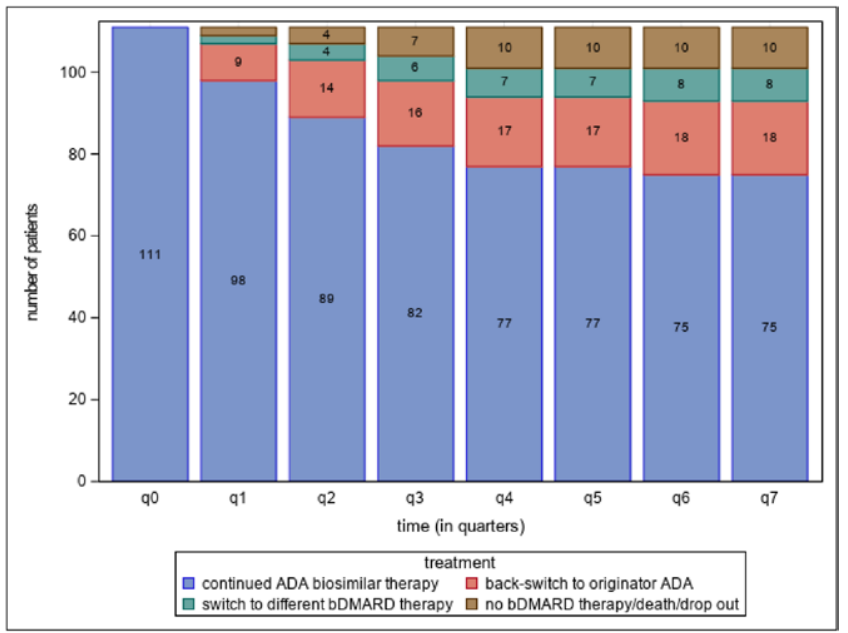

Figure 1. Treatment trajectories of ADA therapy in patients with CIRD during two yearsADA: adalimumab; bDMARD: biological disease modifying anti-rheumatic drug

Disclosure of Interests: None declared

DOI: 10.1136/annrheumdis-2021-eular.1838

\section{$\mathrm{AB} 0824$ \\ ANALYSIS OF GUT MICROBIOTA IN RHEUMATOID ARTHRITIS PATIENTS}

Q. Wang ${ }^{1,2}$, S. X. Zhang ${ }^{3,4,5}$, J. Qiao ${ }^{3,4,5}$, G. Shi ${ }^{1}$, R. Zhao ${ }^{3,4,5}$, S. Song ${ }^{3,4,5}$, Y. Zhang ${ }^{3,4,5}$, Q. Yu ${ }^{2,6}$, X. LI ${ }^{3,4,5}$, P. F. He ${ }^{2} .{ }^{1}$ Shanxi Medical University, Basic Medical College, Taiyuan, China; ${ }^{2}$ Shanxi Medical University, Medical Data Sciences, Taiyuan, China; ${ }^{3}$ The Second Hospital of Shanxi Medical University, Department of Rheumatology, Taiyuan, China; ${ }^{4}$ Shanxi Li Xiaofeng Medical Groups, Department of Rheumatology, Taiyuan, China; ${ }^{5}$ Ministry of Education, Key Laboratory of Cellular Physiology at Shanxi Medical University, Taiyuan, China; ${ }^{6}$ Shanxi Medical University, School of Management, Taiyuan, China

Background: Gastrointestinal microbiota, particularly gut microbiota is an indispensable environmental factor in the progression of Rheumatoid Arthritis (RA) Understanding the diversity and function of the intestinal flora in patients with RA is part and parcel to understand the relationship between microbiota and human health.

Objectives: This study aimed to identify the diversity and function of the intestinal flora in patients with RA.

Methods: A total of 166 participants were recruited in this study, comprising 93 RA patients and 73 age and sex-matched healthy controls (HCs). Microbial genome was extracted from approximately $250 \mathrm{mg}$ fresh fecal samples from all participants using QIAamp PowerFecal DNA Kit (Qiagen). The V3-V4 variable regions of bacterial 16S rRNA genes were sequenced with the Illumina Miseq PE300 system. Sequence data were compiled and processed using Qiime2. Sequences were grouped into operational taxonomic units (ASVs) ${ }^{1}$. Microbial diversity was estimated by the Simpson index. PICRUSt2 was used to predict KEGG functional pathway differences between RA and $\mathrm{HC}$ intestinal flora functions based on ASV Tables ${ }^{2}$. Linear Discriminant Analysis (LDA) Effect Size (LEfSe) analysis was performed using LEfSe software to discovery the different intestinal flora and functions between RA and healthy.

Results: The alpha-diversity index of Simpson the microbiome in RA patients was lower than that of HCs (Figure 1a, $P<0.05$ ). Compared with $\mathrm{HCs}$, bacterial Bacilli and Lactobacillales were more abundant in patients with RA (Figure 1b, $P<0.05)$. In contrast, Marinifilaceae, Peptococcaceae, Peptococcales and Phascolarcto bacterium were less abundant in the RA group (Figure 1b, $P<0.05$ ). As shown in Figure 1c, propanoate metabolism, taurine and hypotaurine metabolism, ascorbate and aldarate metabolism, biosynthesis of siderophore group nonribosomal peptides and glutathione metabolism were the most significantly altered pathways in RA $(P<0.05)$. Epithelial cell signaling in Helicobacter pylori infection, RNA transport, RNA degradation and plant-pathogen interaction were the most significantly altered pathways in $\mathrm{HC}(P<0.05)$. The different KEGG metabolic pathways were mainly concentrated in carbohydrate and amino acid metabolism.

Conclusion: Gut dysbiosis in RA patients mainly characterized by reduced the diversity and impaired abundance of the intestinal flora, which severely influence the metabolism of gastrointestinal microbiota. The discovery of the associated intestinal microbiota of RA may provide a new idea for RA treatment.

\section{REFERENCES:}

[1] Han L, Zhao K, Li Y, et al. A gut microbiota score predicting acute graft-versus-host disease following myeloablative allogeneic hematopoietic stem cell transplantation. Am J Transplant 2020;20(4):1014-27. doi: 10.1111/ajt.15654 [published Online First: 2019/10/13]

[2] Liss MA, White JR, Goros M, et al. Metabolic Biosynthesis Pathways Identified from Fecal Microbiome Associated with Prostate Cancer. Eur Uro 2018;74(5):575-82. doi: 10.1016/j.eururo.2018.06.033 [published Online First: 2018/07/17]

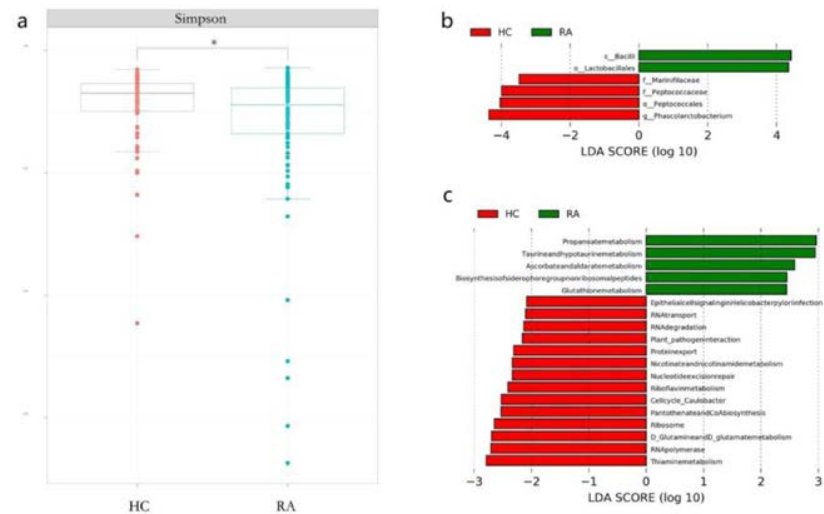

Figure 1 (a) Comparison of Simpson index between HC and RA groups was shown using boxplot. (b) LEFSe was used to detect difference in Flora according to RA and HC. (c) LEISe was used to detect difference in Flora functions according to RA and HC. Pathway differences plot as LDA score (log 10). Bars to the right of zero represent bacterial functions

Acknowledgements: This project was supported by National Science Foundation of China (82001740), Open Fund from the Key Laboratory of Cellular Physiology (Shanxi Medical University) (KLCP2019) and Innovation Plan for Postgraduate Education in Shanxi Province (2020BY078).

Disclosure of Interests: None declared

DOI: 10.1136/annrheumdis-2021-eular.1944

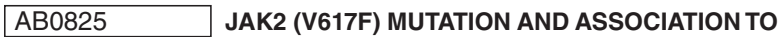 IMMUNE MEDIATED DISEASES. STUDY OF 130 PATIENTS FROM A SINGLE UNIVERSITY HOSPITAL}

C. Álvarez-Reguera ${ }^{1}$, L. Sanchez-Bilbao ${ }^{1}$, A. Batlle-López ${ }^{2}$, S. Fernández López ${ }^{2}$, M. Á. González-Gay ${ }^{1}$, R. Blanco ${ }^{1}{ }^{1}$ Hospital Universitario Marqués de Valdecilla, Rheumatology, Santander, Spain; ${ }^{2}$ Hospital Universitario Marqués de Valdecilla, Hematology, Santander, Spain

Background: Janus Kinases (JAK) are tirosin-kinases that can promote cytokine production in immune and hematopoietic cells. The JAK-2 (V617F) mutation is the most frequently detected mutation in myeloproliferative neoplasms (MPN) which include essential thrombocythemia (ET), polycythemia vera (PV), primary myelofibrosis (PMF) and undifferenciated MPN. JAK-2 (V617F) mutation displays a pro-inflammatory phenotype that may be associated to a higher risk of immune mediated diseases (IMID), thromboembolic complications or other cancers (1-3). Objectives: To evaluate the presence of a) IMID (rheumatic and non-rheumatic) b) cancer and, c) Deep vein thrombosis/ Venous thromboembolism (DVT/VTE) events in a cohort of patients with a positive JAK-2 (V617F) mutation.

Methods: We studied all the patients diagnosed with a positive JAK-2 (V16F) mutation in a single University Hospital between January, 2004 and December 2019

Results: The study included 130 patients (73 men/57 women; mean age, $70.1 \pm 14.5$ years). They were diagnosed of ET $(n=64,49.2 \%)$, PV $46(35.4 \%)$ undifferentiated MPN $(n=12,9.2 \%)$ and PMF $(n=8,6.1 \%)$. Of these patients, 54 (41.5\%) (44 non rheumatic and 10 rheumatic) were diagnosed with at least one IMID, $46(35.4 \%)$ with other cancer different of MPN and $36(27.7 \%)$ with DVT/ VTE events. (Table 1/Figure 1).

Conclusion: Due to its prevalence and potential complications, IMID should be taken into consideration when a patient is diagnosed with a positive JAK-2 (V617F) mutation.

REFERENCES:

[1] Perner F, et al. Cells. 2019;8:854.

[2] Xu Q, et al. Clin Rheumatol. 2020 Jul 16. 